\title{
FOXD3-AS1/miR-128-3p/LIMK1 axis regulates cervical cancer progression
}

\author{
XIUFANG YANG ${ }^{1}$, HUILAN DU ${ }^{2}$, WENHUI BIAN ${ }^{3}$, QINGXUE LI $^{4}$ and HAIRU SUN ${ }^{1}$ \\ ${ }^{1}$ Department of Gynecology, Hengshui People's Hospital, Hengshui, Hebei 053000; ${ }^{2}$ Department of Gynecology, \\ Hebei University of Chinese Medicine; ${ }^{3}$ Department of Gynecology, Chinese Medicine Hospital of Hebei; \\ ${ }^{4}$ Department of Gynecology, The Fourth Hospital of Shijiazhuang, Shijiazhuang, Hebei 050000, P.R. China
}

Received October 16, 2020; Accepted February 5, 2021

DOI: 10.3892/or.2021.8013

\begin{abstract}
Long non-coding RNA forkhead box D3 antisense RNA 1 (FOXD3-AS1) functions as an oncogenic regulator in several types of cancer, including breast cancer, glioma and cervical cancer. However, the effects and mechanisms underlying FOXD3-AS1 in cervical cancer (CC) are not completely understood. The present study aimed to investigate the biological functions and potential molecular mechanisms underlying FOXD3-AS1 in CC progression. Reverse transcription-quantitative PCR was performed to detect FOXD3-AS1, microRNA (miR)-128-3p and LIM domain kinase 1 (LIMK1) expression levels in $\mathrm{CC}$ tissues and cells. Immunohistochemical staining and western blotting were conducted to assess LIMK1 protein expression levels in CC tissues and cells, respectively. Cell Counting Kit- 8 and BrdU assays were used to determine the role of FOXD3-AS1 in regulating cell proliferation. $\mathrm{CC}$ cell migration and invasion were assessed by performing Transwell assays. Dual-luciferase reporter assays were conducted to verify the binding between miR-128-3p and FOXD3-AS1. FOXD3-AS1 expression was significantly increased in CC tissues and cell lines compared with adjacent healthy tissues and normal cervical epithelial cells, respectively. High FOXD3-AS1 expression was significantly associated with poor differentiation of tumor tissues, increased tumor size and positive lymph node metastasis. FOXD3-AS1 overexpression significantly increased $\mathrm{CC}$ cell proliferation, migration and invasion compared with the negative control (NC) group, whereas FOXD3-AS1 knockdown resulted in the opposite effects compared with the small interfering RNA-NC group. Moreover, the results demonstrated that FOXD3-AS1 targeted and negatively regulated miR-128-3p, which indirectly upregulated LIMK1 expression. Therefore, the present study
\end{abstract}

Correspondence to: Dr Xiufang Yang, Department of Gynecology, Hengshui People's Hospital, 180 People's Road, Taocheng, Hengshui, Hebei 053000, P.R. China

E-mail: yangxiufanghengs@126.com

Key words: cervical cancer, forkhead box D3 antisense RNA 1, microRNA-128-3p, LIM domain kinase 1 demonstrated that FOXD3-AS1 upregulated LIMK1 expression via competitively sponging miR-128-3p in CC cells, promoting CC progression.

\section{Introduction}

Cervical cancer (CC) is a commonly diagnosed tumor among females, resulting in $>500,000$ new cases annually worldwide (1-3). Investigating the mechanism underlying CC pathogenesis is important for developing novel biomarkers and therapeutic targets for CC.

Long non-coding RNAs (lncRNAs) were originally considered to be transcriptional noise, but an increasing number of studies have demonstrated that lncRNAs serve a significant regulatory role in human diseases, including numerous types of cancer, including gallbladder cancer, gastric cancer and lung squamous cell carcinoma (4-7). lncRNA forkhead box D3 antisense RNA 1 (FOXD3-AS1) is abnormally expressed in neuroblastoma, breast cancer and glioma, functioning as an oncogenic factor or tumor suppressor (8-10). However, the functions and mechanism underlying FOXD3-AS1 in CC are not completely understood.

MicroRNAs (miRNAs/miRs) can bind to the 3'-untranslated regions of target $\mathrm{mRNAs}$, promoting mRNA degradation or inhibiting mRNA translation (11). miRNAs are involved in regulating a series of biological processes, and dysregulated miRNA expression is a common event in tumorigenesis and cancer progression $(12,13)$. miRNAs are also important regulators of CC pathogenesis (14-17). For example, miR-20a regulates $\mathrm{CC}$ cell proliferation, apoptosis and autophagy by targeting thrombospondin 2 (14). miR-15b upregulation is indicative of poor prognosis in patients with CC (15). Additionally, it has been reported that the expression of miR-128-3p is downregulated in $\mathrm{CC}$ tissues, whereas miR-128-3p overexpression significantly inhibits $\mathrm{CC}$ cell proliferation, migration and invasion (18). However, the mechanism underlying the effects of miR-128-3p in CC requires further investigation.

LIM domain kinase 1 (LIMK1) is a serine/threonine kinase that is involved in the activation of the cell division cycle 42/myotonic dystrophy-Related Cdc42-binding kinase, Rac/p21 activated kinase 1 and ras homolog family member A/Rho associated coiled-coil containing protein kinase 1 signaling pathways, and can regulate cytoskeletal remodeling $(19,20)$. 
Recent studies have demonstrated that LIMK1 expression is upregulated or abnormally activated in various types of cancer, including breast, prostate and colorectal cancer (21-23). Moreover, LIMK1 expression is also significantly upregulated in CC, which is associated with unfavorable prognosis (24). However, the mechanism underlying dysregulated expression of LIMK1 in CC is not completely understood.

The present study aimed to explore the expression and biological functions of FOXD3-AS1 in CC, and to determine its regulatory effect on miR-128-3p and LIMK1.

\section{Materials and methods}

FOXD3-AS1 expression analysis. The Gene Expression Profiling Interactive Analysis (GEPIA) database (gepia. cancer-pku.cn/) was used to predict the expression level of FOXD3-AS1 in patients with CC.

Tissue samples. The present study was approved by the Ethics Committee of Hengshui People's Hospital (approval no. H20150019). Written informed consent was obtained from all patients. A total of 60 female patients with CC (age range, 29-67 years) who underwent surgery at the Hengshui People's Hospital (Hebei, China) between May 2015 and May 2019 were recruited. Paired cancerous tissue and corresponding adjacent healthy tissue (distance from tumor margin, $>3 \mathrm{~cm}$ ) samples were obtained. All samples were confirmed by pathological diagnosis. Patients had not received treatment prior to surgery. All tissue samples were preserved in liquid nitrogen at $-196^{\circ} \mathrm{C}$ until RNA extraction.

Cell culture and cell transfection. Human CC cell lines (C33A, HeLa, HT-3 and SiHa) and a normal cervical epithelial cell line (HCE 16/3) were obtained from The Cell Bank of Type Culture Collection of The Chinese Academy of Sciences. Cells were cultured in DMEM (Gibco; Thermo Fisher Scientific, Inc.) supplemented with 10\% FBS (Gibco; Thermo Fisher Scientific, Inc.) and $1 \%$ penicillin $(100 \mathrm{U} / \mathrm{ml}) /$ streptomycin $(100 \mu \mathrm{g} / \mathrm{ml})$ at $37^{\circ} \mathrm{C}$ with $5 \% \mathrm{CO}_{2}$.

Empty pcDNA3.1 plasmid, pcDNA3.1-FOXD3-AS1, small interfering (si)RNA negative control (NC; si-NC; 5'-CCTCCA GTGACCGCCTAAG-3') and si-FOXD3-AS1 (si-FOXD3-AS1-1, 5'-CTCCAAGATTTAACTTCCA-3'; si-FOXD3-AS1-2, 5'-GGA GTTCCGAGAGGAAATA-3'; si-FOXD3-AS1-3, 5'-GATGCT GGGATGTGGATTT-3') were prepared by Guangzhou RiboBio Co., Ltd. miRNA mimics control (NC mimics, 5'-ACGUGACAC GUUCGGAGAATT-3'), miR-128-3p mimics (5'-AAGAGACCG UUCACUGUGA-3'), miRNA inhibitors control (NC inhibitors, 5'-CUAACGCAUGCACAGUCGUACG-3') and miR-128-3p inhibitors (5'-UUUCUCUGGCCAAGUGACACU-3') were obtained from Shanghai GenePharma Co., Ltd. HeLa and C33A cells in the logarithmic growth phase were harvested and resuspended in antibiotic-free and serum-free medium. Subsequently, cell suspension $\left(5 \times 10^{5}\right.$ cells $\left./ \mathrm{ml}\right)$ was added to 6 -well plates. Cells were transfected with plasmids $(1.5 \mu \mathrm{g} / \mathrm{ml})$, siRNAs $(100 \mathrm{nM})$ or miRNAs $(50 \mathrm{nM})$ using Lipofectamine ${ }^{\circledR} 3000$ (Invitrogen; Thermo Fisher Scientific, Inc.) at $37^{\circ} \mathrm{C}$ for $24 \mathrm{~h}$. Cells were cultured in complete medium supplemented with $10 \%$ FBS. Following culture for $24 \mathrm{~h}$, cells were harvested and transfection efficiency was assessed.
Reverse transcription-quantitative PCR (RT-qPCR). Total RNA was extracted from tissues and cells using TRIzol ${ }^{\circledR}$ reagent (Invitrogen; Thermo Fisher Scientific, Inc.). RNA concentrations were determined using a NanoDrop1000 spectrophotometer (Thermo Fisher Scientific, Inc.). RNA was reverse transcribed into cDNA using a PrimeScript RT Master Mix kit (Takara Bio, Inc.) according to the manufacturer's protocol. Subsequently, cDNA was used for qPCR using SYBR Green MasterMix kit (Takara Bio, Inc.) and an ABI 7900 Fast Real-Time PCR System (Applied Biosystems; Thermo Fisher Scientific, Inc.). The thermocycling conditions used for qPCR were as follows: Initial denaturation at $94^{\circ} \mathrm{C}$ for $5 \mathrm{~min} ; 40$ cycles of denaturation at $94^{\circ} \mathrm{C}$ for $30 \mathrm{sec}$, annealing at $62^{\circ} \mathrm{C}$ for $45 \mathrm{sec}$ and extension at $72^{\circ} \mathrm{C}$ for $40 \mathrm{sec}$; and final extension at $72^{\circ} \mathrm{C}$ for $7 \mathrm{~min}$. The sequences of the primers used for qPCR are presented in Table I. FOXD3-AS1 and LIMK1 mRNA expression levels were normalized to the internal reference gene GAPDH. miR-128-3p expression levels were normalized to the internal reference gene U6. Gene expression levels were quantified using the $2^{-\Delta \Delta \mathrm{Cq}}$ method (25).

Isolation of cytoplasmic and nuclear RNA. Subcellular isolation of RNA from HeLa and C33A cells was performed using the Cytoplasmic and Nuclear RNA Purification kit (Thermo Fisher Scientific, Inc.) according to the manufacturer's protocol. Cytoplasmic and nuclear fraction expression levels were determined via qPCR according to the aforementioned protocol. U6 was utilized as nuclear RNA control and GAPDH as cytoplasmic control.

Cell Counting Kit-8 (CCK-8) assay. Transfected HeLa and C33A cells were collected and seeded $\left(2 \times 10^{3}\right.$ cells/well) into 96-well plates. Following culture for 12, 24, 48, 72 or $96 \mathrm{~h}$, $10 \mu \mathrm{l}$ CCK-8 solution (Dojindo Molecular Technologies, Inc.) was added to each well and incubated for $2 \mathrm{~h}$. The optical density was measured at a wavelength of $450 \mathrm{nM}$ using a microplate reader (BioRad Laboratories, Inc.).

BrdU assay. BrdU cell proliferation assay kit (Cell Signaling Technology Inc.) was used for BrdU cell proliferation assay. Transfected C33A and HeLa cells were seeded $\left(5 \times 10^{3}\right.$ cells $\left./ \mathrm{ml}\right)$ into 96-well plates and cultured overnight. Subsequently, $20 \mu 1$ BrdU solution (Beyotime Institute of Biotechnology) was added to each well and incubated for $12 \mathrm{~h}$. Subsequently, the culture medium was discarded and cells were washed with PBS. Cells were fixed with $4 \%$ paraformaldehyde for $30 \mathrm{~min}$ at room temperature and washed again with PBS. Cells were incubated with anti-BrdU (cat. no. ab6326; 1:2,000; Abcam) for $1 \mathrm{~h}$ at room temperature. Then, cell nuclei were counterstained using Hoechst staining solution (Beyotime Institute of Biotechnology) at room temperature for $30 \mathrm{~min}$. BrdU ${ }^{+}$cells were observed and counted using a fluorescence microscope (CX41-32RFL; Olympus Corporation).

Transwell assay. Transwell chamber inserts (pore size, $8.0 \mu \mathrm{m}$; EMD Millipore) were used to assess cell migration and invasion. To assess cell invasion, the upper chambers of the Transwell inserts were precoated with Matrigel (BD Biosciences) for $1 \mathrm{~h}$ at room temperature. To assess cell migration, the upper chambers of the Transwell inserts were not precoated with 
Table I. Sequences of primers used for quantitative PCR.

\begin{tabular}{ll}
\hline Gene & \multicolumn{1}{c}{ Sequence $\left(5^{\prime} \rightarrow 3^{\prime}\right)$} \\
\hline FOXD3-AS1 & F: GGTGGAGGAGGCGAGGATG \\
& R: GGTGGAGGAGGCGAGGATG \\
miR-128-3p & F: GACTGCCGAGCGAGCG \\
& R: GACGCCGAGGCACTCTCTCCT \\
LIMK1 & F: GGGGCATCATCAAGAGCA \\
& R: CCAGGCAGTTGTGGGAGT \\
GAPDH & F: TGGGCTACACTGAGCACCAG \\
& R: GGGTGTCGCTGTTGAAGTCA \\
U6 & F: CCATCGGAAGCTCGTATACGAAATT \\
& R: GGCCTCTCGAACTTGCGTGTCAG
\end{tabular}

FOXD3-AS1, forkhead box D3 antisense RNA 1; miR, microRNA; LIMK1, LIM domain kinase 1; F, forward; R, reverse.

Matrigel. Transfected HeLa and C33A cells $\left(2 \times 10^{4}\right.$ cells/well) resuspended in serum-free DMEM were added to the upper chamber. The lower chamber was filled with DMEM supplemented with $10 \% \mathrm{FBS}$. Following incubation at $37^{\circ} \mathrm{C}$ for $24 \mathrm{~h}$, a cotton swab was used to remove non-migratory/invading cells in the upper chamber. Migratory/invading cells were fixed using $4 \%$ paraformaldehyde for $30 \mathrm{~min}$ at room temperature and stained with $0.1 \%$ crystal violet solution for $30 \mathrm{~min}$ at room temperature. Cells were counted using a light microscope (Nikon Corporation).

Luciferase reporter assay. The possible target miRNAs of FOXD3-AS1 were predicted using StarBase (starbase.sysu. edu.cn). The cDNA fragment containing the wild-type (WT; FOXD3-AS1-WT) or mutant (MUT; FOXD3-AS1-MUT) FOXD3-AS1 fragment was subcloned downstream of the luciferase gene in psi-CHECK luciferase reporter vectors (Promega Corporation). HeLa and C33A cells were co-transfected $\left(4 \times 10^{4}\right.$ cells/well) with $100 \mathrm{nM}$ luciferase reporter vectors and $50 \mathrm{nM}$ miR-128-3p mimics or miRNA mimics control using Lipofectamine $^{\circledR} 3000$ (Invitrogen; Thermo Fisher Scientific, Inc.) at room temperature for $24 \mathrm{~h}$. Luciferase activities were measured using a dual-luciferase reporter gene system (Promega Corporation) according to the manufacturer's protocol. Firefly luciferase activity was normalized to Renilla luciferase activity.

RNA immunoprecipitation (RIP). RIP analysis was performed using a Magna RIP RNA binding protein immunoprecipitation kit (EMD Millipore). At $48 \mathrm{~h}$ post-transfection, HeLa and C33A cells were lysed with RIP lysis buffer (EMD Millipore). Cell lysate $\left(2 \times 10^{7}\right.$ cells) was incubated with protein A magnetic beads (EMD Millipore) conjugated to anti-argonaute RISC catalytic component 2 (Ago2; cat. no. ab32381; 1:500; Abcam) or anti-IgG (cat. no. ab172730; 1:500; Abcam) antibody. After $6 \mathrm{~h}$, the beads $(50 \mu \mathrm{l})$ were washed four times with RIP buffer, and then incubated with $0.1 \% \mathrm{SDS} / 0.5 \mathrm{mg} / \mathrm{ml}$ Proteinase K for $30 \mathrm{~min}$ at $55^{\circ} \mathrm{C}$ to remove proteins. After purification, the enrichment of FOXD3-AS1 and miR-128-2p was assessed via qPCR according to the aforementioned protocol.
Immunohistochemistry. $\mathrm{CC}$ tissues and corresponding adjacent healthy tissues were fixed with $10 \%$ formalin for $60 \mathrm{~min}$ at room temperature and embedded in paraffin. Paraffin sections (thickness, $4 \mu \mathrm{m}$ ) were de-paraffinized with xylene and hydrated using a descending ethanol series. Antigen retrieval was performed by heating $\left(98^{\circ} \mathrm{C}\right)$ in $10 \mathrm{mM}$ sodium citrate-hydrochloric acid buffer ( $\mathrm{pH}$ 8.0) for $30 \mathrm{~min}$. Following incubation in $3 \% \mathrm{H}_{2} \mathrm{O}_{2}$ solution to quench endogenous peroxidase activity, samples were incubated with normal goat serum (cat. no. ab7481; 1:100; Abcam) for 20 min to block non-specific binding at room temperature. Subsequently, samples were incubated with a primary antibody targeted against anti-LIMK1 (cat. no. 19699-1-AP; 1:100; ProteinTech Group, Inc.) overnight at $4^{\circ} \mathrm{C}$. Following washing with PBS, samples were incubated with rabbit IgG monoclonal secondary antibody (cat. no. ab172730; 1:500; Abcam) for $1 \mathrm{~h}$ at room temperature. Subsequently, samples were washed with PBS again and then stained with 3,3-diaminobenzidine hydrochloride for $15 \mathrm{~min}$ at room temperature. Stained sections were observed and scored by two independent pathologists using a light microscope (Olympus Corporation) using a double-blind method. Scoring criteria were based on staining intensity and the percentage of stained cells. The expression score was calculated according to the following formula: Percentage of stained cells $(0$, no staining, $1,<25$ positively stained cells; $2,25-50 \%$ positively stained cells; and $3,>50 \%$ positively stained cells) + staining intensity score ( 0 , no staining; 1 , faint; 2 , moderate; and 3 , strong). The expression score was categorized as negative $(0-2)$ or positive $(\geq 2)$.

Western blotting. Transfected C33A and HeLa cells were collected and lysed using RIPA lysis buffer (Beyotime Institute of Biotechnology). Protein concentrations were determined using a bicinchoninic assay kit (Bio-Rad Laboratories, Inc.). Proteins $(15 \mu \mathrm{g})$ were separated via SDS-PAGE (10\% separation gel and $4 \%$ concentration gel) and transferred to PVDF membranes (EMD Millipore). Following blocking with $5 \%$ skimmed milk for $2 \mathrm{~h}$ at room temperature, the membranes were incubated with anti-LIMK1 (cat. no. ab81046; 1:1,000; Abcam) or anti-GAPDH (cat. no. ab181602; 1:1,000; Abcam) primary antibodies overnight at $4^{\circ} \mathrm{C}$. Following washing with TBST $(0.1 \%$ Tween-20), the membranes were incubated with a horseradish peroxidase-conjugated secondary rat monoclonal IgG antibody (cat. no. sc-69916; 1:2,000; Santa Cruz Biotechnology, Inc.) for $1 \mathrm{~h}$ at room temperature. Protein bands were visualized using an ECL substrate kit (Amersham; Cytiva). GAPDH was used as the loading control.

Statistical analysis. Statistical analyses were performed using SPSS software (version 17.0; SPSS Inc.). All experiments were performed in triplicate. Data are presented as the mean \pm SD. The paired Student's t-test was used to analyze comparisons between paired samples. The unpaired Student's t-test was used to analyze comparisons between unpaired samples. Comparisons among multiple groups were analyzed using one-way ANOVA followed by Tukey's post hoc test. Categorical data were analyzed using the $\chi^{2}$ test. Kaplan-Meier survival analyses and log-rank tests were performed to determine the association between overall survival time and FOXD3-AS1 expression. Pearson's correlation coefficient was used to analyze 
A

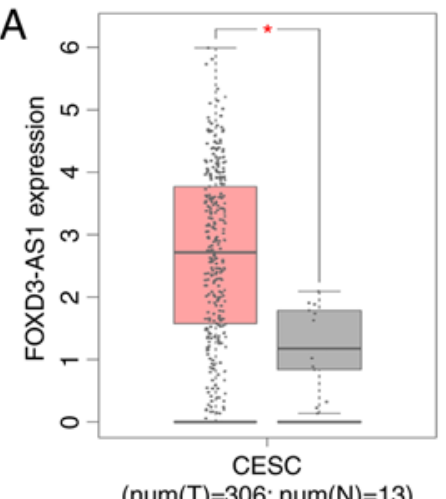

D

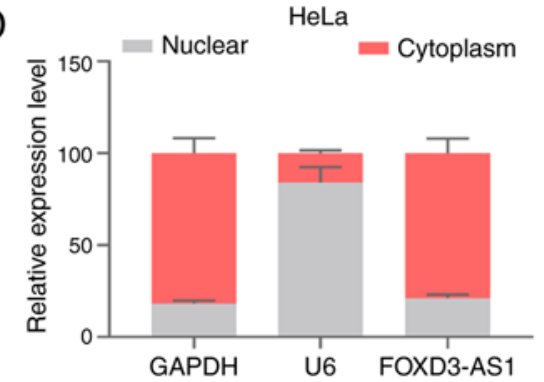

B

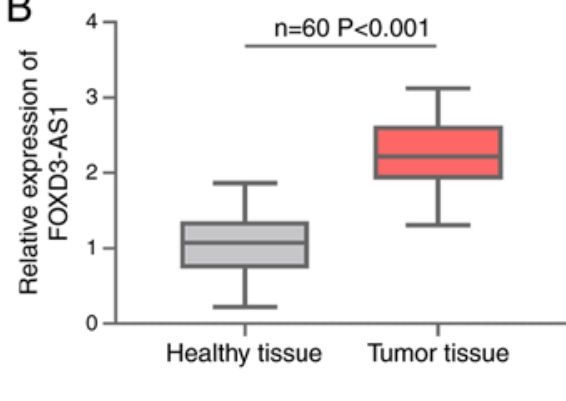

C33A

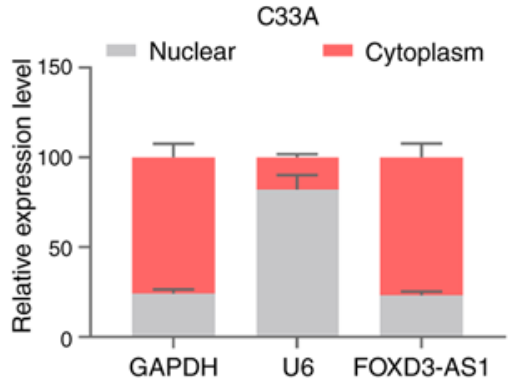

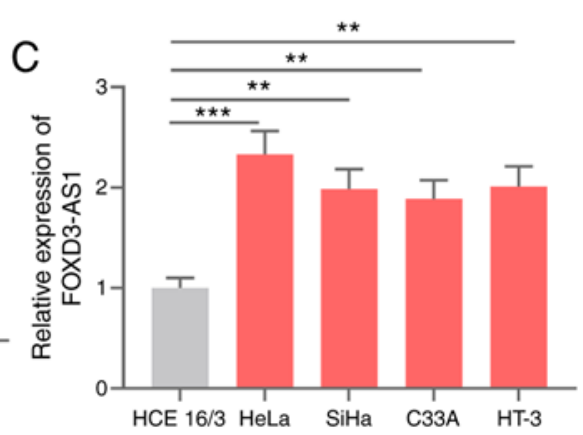

E

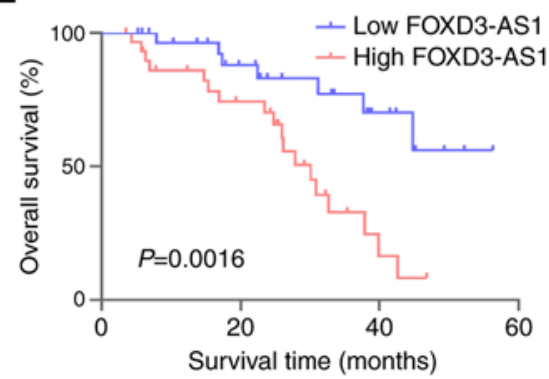

Figure 1. FOXD3-AS1 expression is upregulated in CC tissues and cells. (A) FOXD3-AS1 expression levels in CC tissues and adjacent healthy tissues were obtained from GEPIA database. Reverse transcription-quantitative PCR was performed to assess FOXD3-AS1 expression levels in (B) 60 paired CC tissue and adjacent healthy tissue samples, as well as in (C) normal cervical epithelial and CC cell lines. (D) FOXD3-AS1 mRNA expression levels in the nucleus and cytoplasm. (E) Kaplan-Meier survival analysis and log-rank tests were performed to analyze the association between FOXD3-AS1 expression and the prognosis of patients with $\mathrm{CC} .{ }^{*} \mathrm{P}<0.05,{ }^{* *} \mathrm{P}<0.01$ and ${ }^{* * *} \mathrm{P}<0.001$. FOXD3-AS1, forkhead box D3 antisense RNA 1; CC, cervical cancer; CESC, cervical squamous cell carcinoma and endocervical adenocarcinoma; T, tumor tissue; $\mathrm{N}$, healthy tissue.

the correlation between FOXD3-AS1 and miR-128-3p, LIMK1 and miR-128-3p, and LIMK1 and FOXD3-AS1. P $<0.05$ was considered to indicate a statistically significant difference.

\section{Results}

FOXD3-AS1 expression in CC and its clinical significance. FOXD3-AS1 expression in CC samples was analyzed using data obtained from GEPIA (gepia.cancer-pku.cn/). FOXD3-AS1 expression was significantly upregulated in $\mathrm{CC}$ tissues compared with healthy cervical tissues (Fig. 1A). RT-qPCR was performed to measure FOXD3-AS1 expression levels in $\mathrm{CC}$ tissue and corresponding adjacent healthy tissue samples obtained from 60 patients with CC. Compared with corresponding adjacent healthy tissues, FOXD3-AS1 expression levels were significantly higher in CC tissues (Fig. 1B). Additionally, FOXD3-AS1 expression levels in CC cells (HeLa, SiHa, C33A and HT-3) and normal cervical epithelial cells (HCE 16/3) were determined. Consistent with the tissue analysis, FOXD3-AS1 expression in CC cells was significantly upregulated compared with HCE $16 / 3$ cells (Fig. 1C). Subsequently, the subcellular distribution of FOXD3-AS1 was assessed. The results demonstrated that FOXD3-AS1 was primarily located in the cytoplasm of HeLa and C33A cells compared with the nucleus (Fig. 1D). Kaplan-Meier survival analysis demonstrated that the overall survival time of patients with CC with high FOXD3-AS1 expression was significantly shorter compared with patients with CC with low FOXD3-AS1 expression (Fig. 1E). To determine the clinical significance of high FOXD3-AS1 expression in CC tissues, patients were stratified according to the median expression level $(2.23 \pm 0.19)$ of FOXD3-AS1 in CC tissues. The results indicated that high FOXD3-AS1 expression was significantly associated with larger tumor size $(\mathrm{P}=0.0125)$, poorer tumor differentiation $(\mathrm{P}=0.0048)$ and presence of lymph node metastasis $(\mathrm{P}=0.0195)$ (Table II). The aforementioned results suggested that FOXD3-AS1 displayed a tumor-promoting effect on CC.

FOXD3-AS1 promotes CC cell proliferation, migration and invasion. Among the four $\mathrm{CC}$ cell lines, the expression of FOXD3-AS1 was lowest in C33A cells and highest in HeLa cells. Therefore, C33A cells were used for FOXD3-AS1 overexpression and HeLa cells were used for FOXD3-AS1 knockdown (Fig. 2A). Subsequently, CCK-8 and BrdU assays were performed to assess cell proliferation. FOXD3-AS1 knockdown significantly inhibited HeLa cell proliferation compared with the si-NC group, whereas FOXD3-AS1 overexpression significantly increased $\mathrm{C} 33 \mathrm{~A}$ cell proliferation compared with the NC group (Fig. 2B and C). Transwell assays were conducted to assess $\mathrm{CC}$ cell migration and invasion. Compared with the si-NC group, FOXD3-AS1 knockdown significantly suppressed HeLa cell migration and invasion, whereas FOXD3-AS1 overexpression significantly facilitated C33A cell migration and invasion compared with the NC group (Fig. 2D and E).

FOXD3-AS1 targets miR-128-3p. IncRNAs can regulate miRNAs by serving as competitive endogenous RNAs (26). 
Table II. Association between FOXD3-AS1 expression levels and clinical characteristics of patients with $C C(n=60)$.

\begin{tabular}{|c|c|c|c|c|c|}
\hline \multirow[b]{2}{*}{ Characteristic } & \multirow[b]{2}{*}{$\mathrm{n}$} & \multicolumn{2}{|c|}{$\begin{array}{c}\text { FOXD3-AS1 } \\
\text { expression }\end{array}$} & \multirow[b]{2}{*}{$\chi^{2}$} & \multirow[b]{2}{*}{ P-value } \\
\hline & & High & Low & & \\
\hline Age (years) & & & & 2.5837 & 0.1080 \\
\hline$<40$ & 22 & 8 & 14 & & \\
\hline$\geq 40$ & 38 & 22 & 16 & & \\
\hline Differentiation & & & & 7.9365 & $0.0048^{\mathrm{b}}$ \\
\hline Poor & 42 & 16 & 26 & & \\
\hline Well or moderate & 18 & 14 & 4 & & \\
\hline Tumor size $(\mathrm{cm})$ & & & & 6.2388 & $0.0125^{\mathrm{a}}$ \\
\hline$<4$ & 19 & 14 & 5 & & \\
\hline$\geq 4$ & 41 & 16 & 25 & & \\
\hline Histology & & & & 0.1307 & 0.7177 \\
\hline Squamous & 51 & 26 & 25 & & \\
\hline Adenocarcinoma & 9 & 4 & 5 & & \\
\hline HPV16/18 & & & & 2.7000 & 0.1003 \\
\hline Negative & 40 & 17 & 23 & & \\
\hline Positive & 20 & 13 & 7 & & \\
\hline $\begin{array}{l}\text { Lymph node } \\
\text { metastasis }\end{array}$ & & & & 5.4545 & $0.0195^{\mathrm{a}}$ \\
\hline Negative & 16 & 12 & 4 & & \\
\hline Positive & 44 & 18 & 26 & & \\
\hline
\end{tabular}

FOXD3-AS1, forkhead box D3 antisense RNA 1; CC, cervical cancer; HPV, human papillomavirus. ${ }^{\mathrm{a}} \mathrm{P}<0.05$ and ${ }^{\mathrm{b}} \mathrm{P}<0.01$.

StarBase (starbase.sysu.edu.cn) was used to predict the target miRNAs of FOXD3-AS1. A potential binding site between FOXD3-AS1 and miR-128-3p was identified (Figs. 3A and Table SI). The dual-luciferase reporter assay results demonstrated that miR-128-3p mimics significantly inhibited the luciferase activity of the FOXD3-AS1-WT reporter compared with the NC group, but did not display a significant effect on the luciferase activity of the FOXD3-AS1-MUT reporter (Fig. 3B). The interaction between miR-128-3p and FOXD3-AS1 was further verified by performing RIP assays. The results demonstrated that FOXD3-AS1 and miR-128-3p were significantly enriched in anti-Ago 2 conditions compared with anti-IgG conditions (Fig. 3C). Furthermore, Pearson's correlation coefficient demonstrated a negative correlation between miR-128-3p and FOXD3-AS1 expression in CC tissues (Fig. 3D). miR-128-3p expression was significantly decreased in CC tissues compared with adjacent healthy tissues (Fig. 3E). miR-128-3p expression was significantly lower in the four $\mathrm{CC}$ cell lines compared with normal cervical epithelial cells (Fig. 3F). FOXD3-AS1 knockdown in HeLa cells significantly increased miR-128-3p expression compared with the si-NC group, whereas FOXD3-AS1 overexpression in C33A cells significantly downregulated miR-128-3p expression compared with the NC group (Fig. 3G). Collectively, the results suggested that FOXD3-AS1 adsorbed miR-128-3p and negatively regulated miR-128-3p expression in CC cells.

miR-128-3p suppresses CC cell proliferation, migration and invasion. To investigate the biological function of miR-128-3p in CC cells, HeLa cells were transfected with miR-128-3p inhibitors and C33A cells were transfected with miR-128-3p mimics (Fig. 4A). The CCK-8 and BrdU assay results demonstrated that miR-128-3p knockdown significantly promoted HeLa cell proliferation compared with the NC inhibitors group, whereas miR-128-3p overexpression significantly inhibited C33A cell proliferation compared with the NC group (Fig. 4B and C). Furthermore, the Transwell assay results indicated that miR-128-3p knockdown significantly enhanced HeLa cell migration and invasion compared with the NC inhibitors group, whereas miR-128-3p overexpression significantly reduced $\mathrm{C} 33 \mathrm{~A}$ cell migration and invasion compared with the NC group (Fig. 4D and E). The results suggested that miR-128-3p functioned as a tumor suppressor in CC.

LIMK1 is regulated by the FOXD3-AS1/miR-128-3p axis. It has been reported that LIMK1 is a downstream target of miR-128-3p (27). In the present study, immunohistochemistry was performed to assess LIMK1 expression in CC. The positive expression rate of LIMK1 in CC tissues was significantly higher compared with adjacent healthy tissues (Fig. 5A). RT-qPCR and western blotting were performed to detect LIMK1 mRNA and protein expression levels in $\mathrm{CC}$ tissues and cells. LIMK1 mRNA and protein expression levels were notably upregulated in $\mathrm{CC}$ tissues and cells compared with adjacent healthy tissues and normal cervical epithelial cells, respectively (Fig. 5B-D). In CC tissue samples, LIMK1 mRNA expression was negatively associated with miR-128-3p expression, but positively associated with FOXD3-AS1 expression (Fig. 5E and F). Furthermore, miR-128-3p knockdown markedly upregulated LIMK1 mRNA and protein expression levels in HeLa cells compared with the NC inhibitors group, whereas miR-128-3p overexpression notably downregulated LIMK1 mRNA and protein expression levels in C33A cells compared with the NC group. FOXD3-AS1 knockdown markedly reduced LIMK1 mRNA and protein expression levels in HeLa cells compared with the si-NC group, whereas FOXD3-AS1 overexpression obviously increased LIMK1 mRNA and protein expression levels in C33A cells compared with the NC group (Fig. 5G-J). The results indicated that LIMK1 was regulated by the FOXD3-AS1/miR-128-3p axis in CC.

miR-128-3p partially reverses the effects of FOXD3-AS1. To further elucidate the role of the FOXD3-AS1/miR-128-3p/ LIMK1 axis in CC, miR-128-3p inhibitors were transfected into FOXD3-AS1-knockdown HeLa cells and miR-128-3p mimics were transfected into FOXD-AS1-overexpression C33A cells (Fig. 6A). Functional experiments demonstrated that miR-128-3p inhibitors significantly reversed FOXD3-AS1 knockdown-mediated inhibitory effects on HeLa cell proliferation, migration and invasion, whereas miR-128-3p overexpression significantly inhibited FOXD3-AS1 overexpression-mediated promoting effects on $\mathrm{C} 33 \mathrm{~A}$ cell proliferation, migration and invasion (Fig. 6B-E). Furthermore, 
A

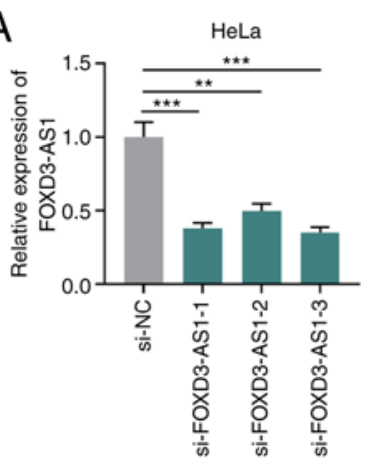

C

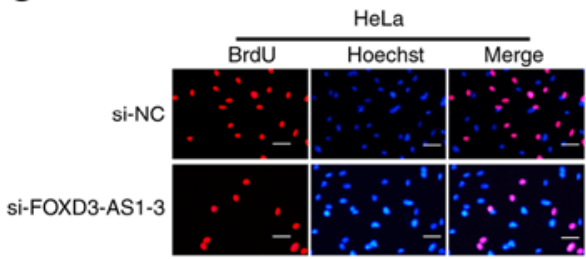

D

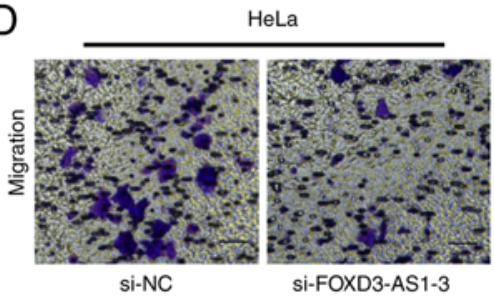

$\mathrm{E}$

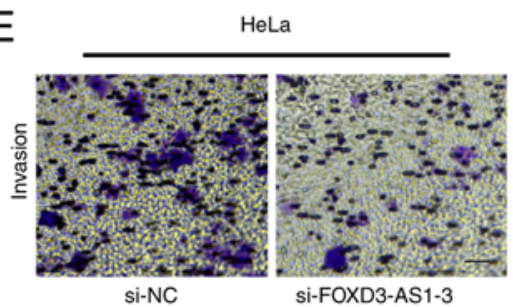

Сз3А

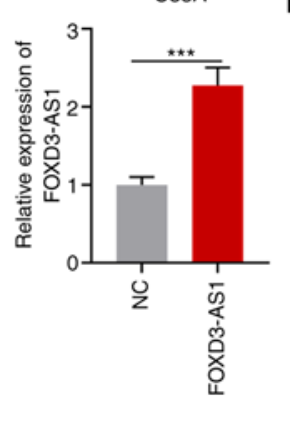

B

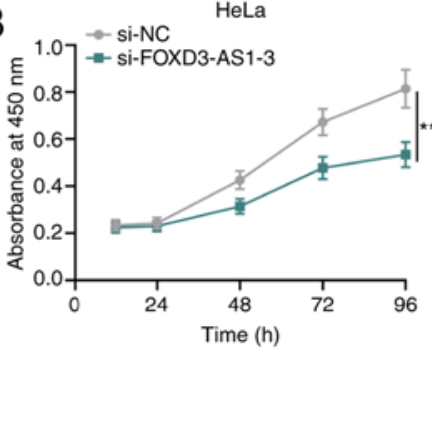

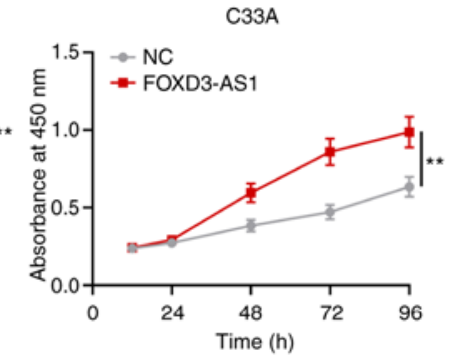
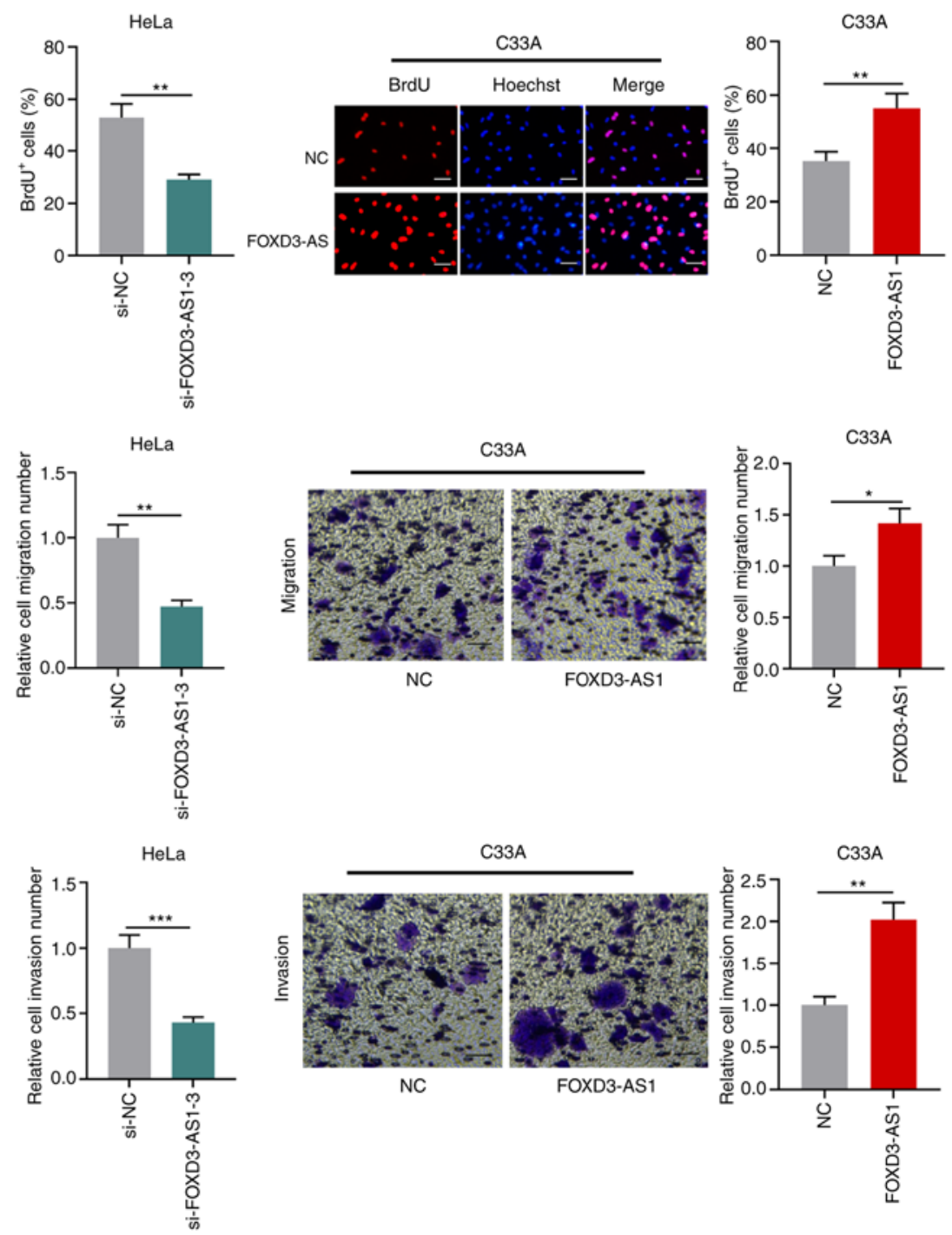

Figure 2. FOXD3-AS1 facilitates CC cell proliferation, migration and invasion. (A) Reverse transcription-quantitative PCR was performed to assess the transfection efficiency of si-FOXD3-AS1-1/2/3 and FOXD3-AS1 overexpression plasmids. (B) Cell Counting Kit-8 and (C) BrdU assays were performed to assess cell proliferation following FOXD3-AS1 knockdown or overexpression (scale bar, $250 \mu \mathrm{m}$ ). Transwell assays were performed to assess the effect of FOXD3-AS1 knockdown and overexpression on cell (D) migration and (E) invasion (scale bar, $100 \mu \mathrm{m}$ ). ${ }^{*} \mathrm{P}<0.05,{ }^{* *} \mathrm{P}<0.01$ and ${ }^{* * * *} \mathrm{P}<0.001$. FOXD3-AS1, forkhead box D3 antisense RNA 1; CC, cervical cancer; si, small interfering RNA; NC, negative control.

miR-128-3p knockdown markedly reversed FOXD3-AS1 knockdown-induced downregulation of LIMK1 mRNA and protein expression levels, whereas miR-128-3p overexpression obviously reversed FOXD3-AS1 overexpression-induced upregulation of LIMK1 mRNA and protein expression levels (Fig. 6F). The results suggested that FOXD3-AS1 participated in promoting CC progression via the miR-128-3p/LIMK1 axis.

\section{Discussion}

In recent years, several studies on IncRNAs have provided a theoretical basis for the progression of CC $(28,29)$. For example, lncRNA-transthyretin expression is upregulated in $\mathrm{CC}$, where it promotes $\mathrm{CC}$ cell malignant biological behaviors by regulating TGF- $\beta$ signaling, and upregulated lncRNA-transthyretin 
A

FOXD3-AS1 WT: 5'-cgcaacuCCGcUccgCACUGUGc-3'

miR-128-3p: 3'-uuucucuGGCcA---aGUGACACu-5'

FOXD3-AS1 MUT: 5'-cgcaacuggGcaccgCgggaccc-3'

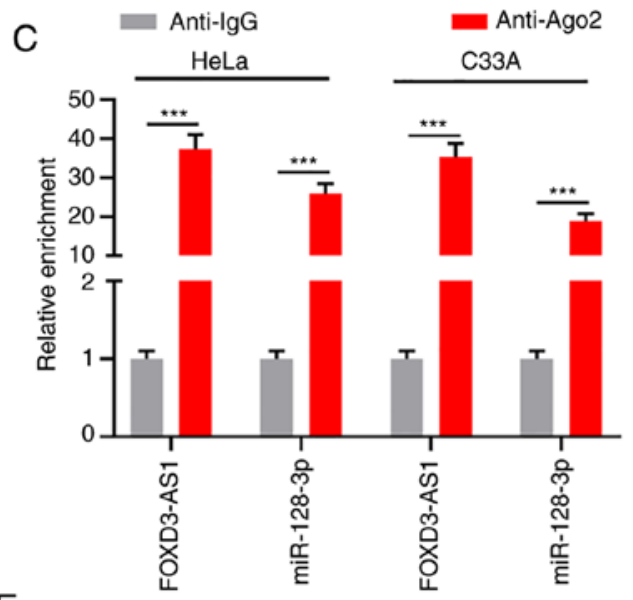

E

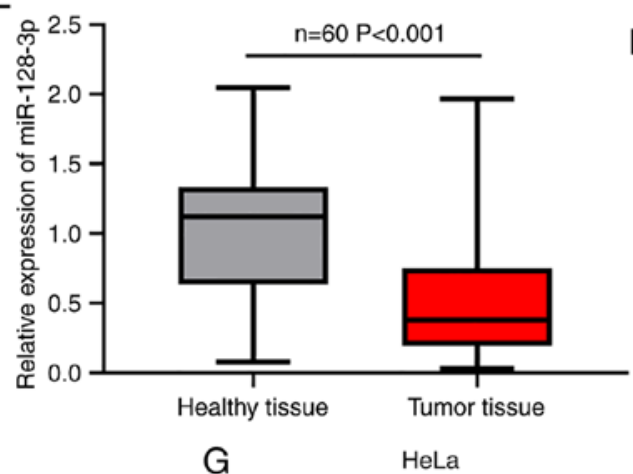

G
B NC mimics $=$ miR-128-3p mimics

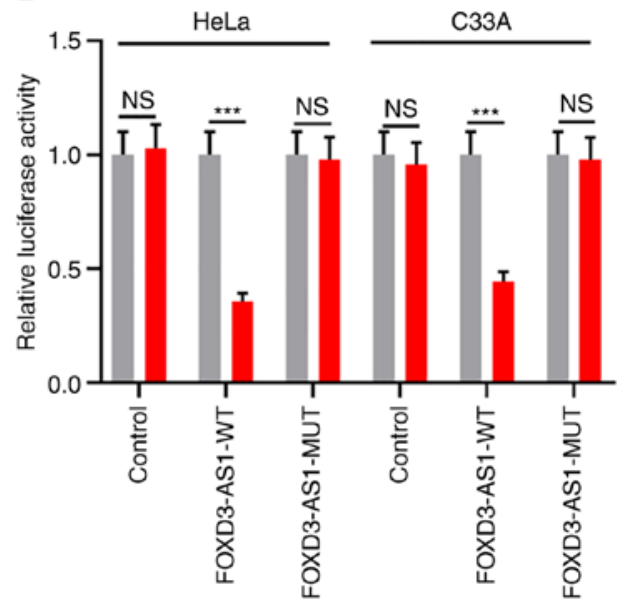

D

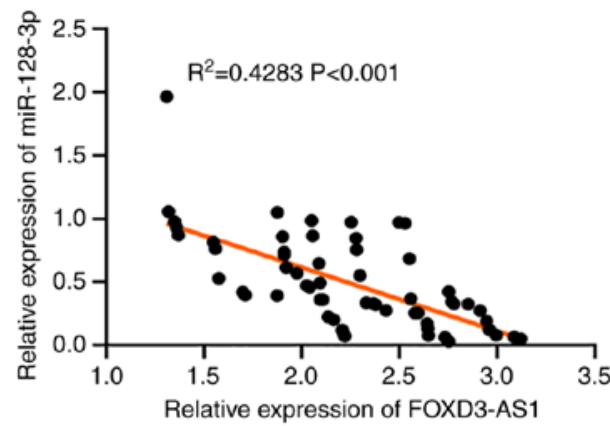

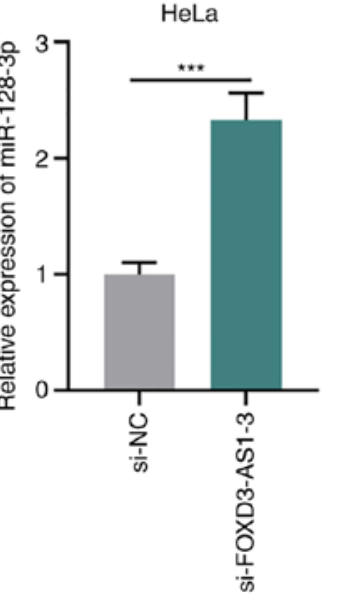

$\mathrm{F}$

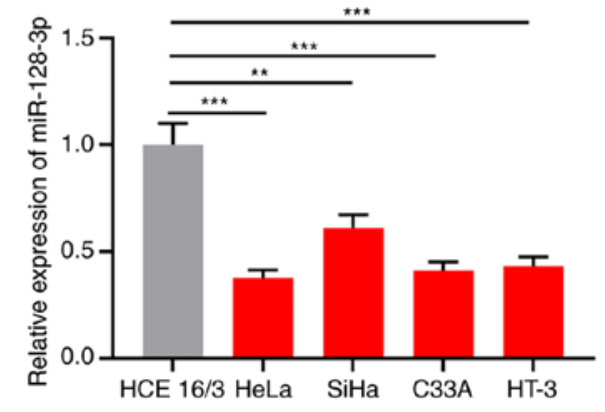

СЗ3А

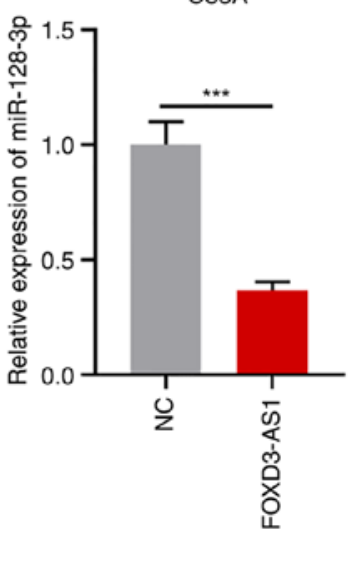

Figure 3. FOXD3-AS1 targets miR-128-3p. (A) Predicted binding site between FOXD3-AS1 and miR-128-3p. (B) Dual-luciferase reporter assays were performed to verify the interaction between FOXD3-AS1 and miR-128-3p. (C) Enrichment of FOXD3-AS1 and miR-128-3p in anti-Ago2 or anti-IgG was determined by conducting RNA immunoprecipitation assays. (D) Correlation between FOXD3-AS1 expression and miR-128-3p expression in CC tissues. RT-qPCR was performed to determine the expression levels of miR-128-3p in (E) CC and adjacent healthy tissues, as well as in (F) normal cervical epithelial and CC cell lines. (G) RT-qPCR was performed to measure miR-128-3p expression levels in CC cells following FOXD3-AS1 knockdown or overexpression. ${ }^{* *} \mathrm{P}<0.01$ and ${ }^{* * * *} \mathrm{P}<0.001$. FOXD3-AS1, forkhead box D3 antisense RNA 1; miR, microRNA; Ago2, argonaute RISC catalytic component 2; CC, cervical cancer; RT-qPCR, reverse transcription-quantitative PCR; NC, negative control; si, small interfering RNA; NS, not significant; WT, wild-type; MUT, mutant. 

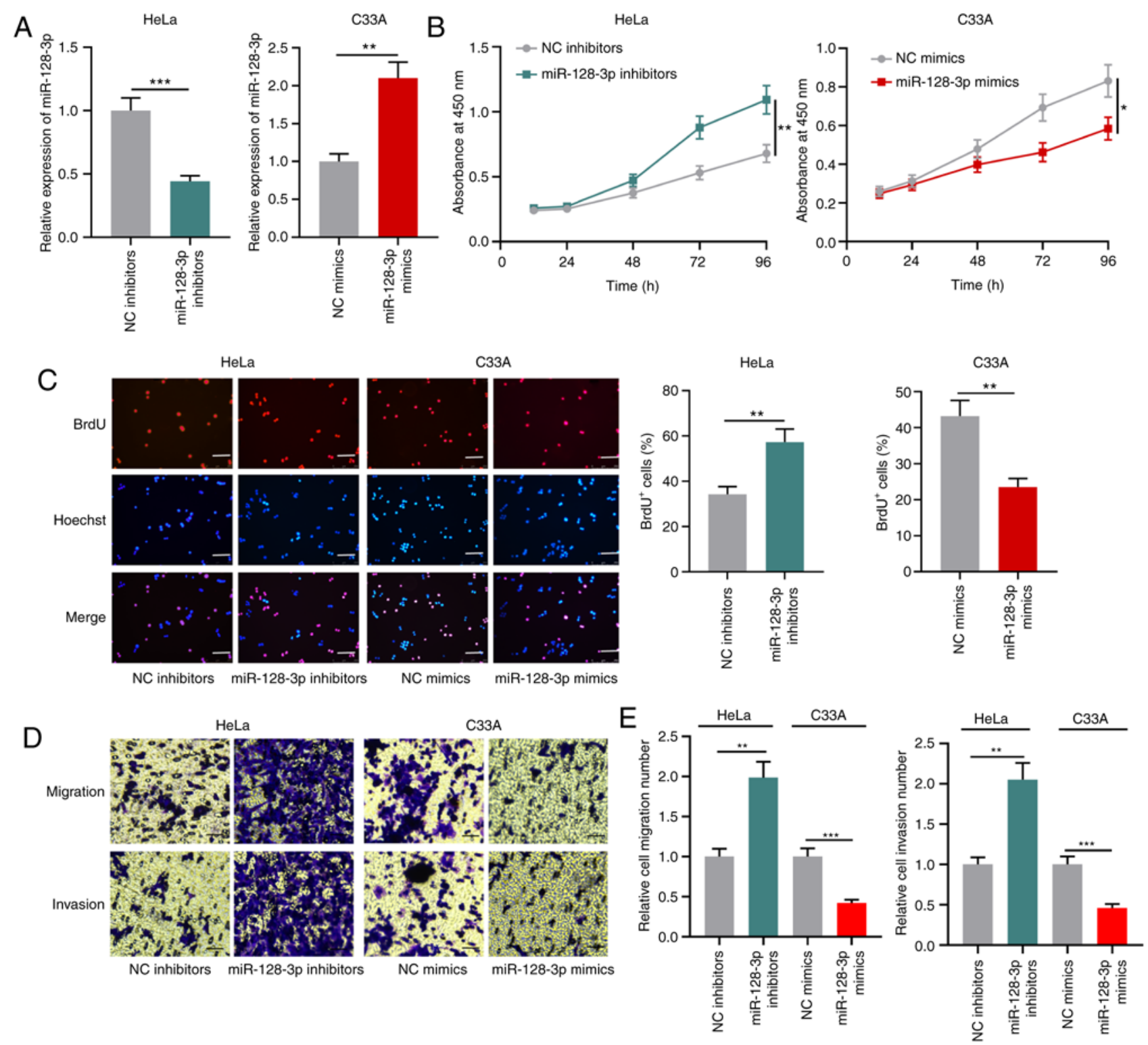

Figure 4. miR-128-3p regulates CC cell proliferation, migration and invasion. (A) Reverse transcription-quantitative PCR was performed to measure miR-128-3p expression levels in miR-128-3p inhibitors-transfected HeLa cells and miR-128-3p mimics-transfected C33A cells. (B) Cell Counting Kit-8 and (C) BrdU assays were performed to detect CC cell proliferation following transfection (scale bar, $250 \mu \mathrm{m}$ ). Cell migration and invasion were (D) determined by performing Transwell assays (scale bar, $100 \mu \mathrm{m}$ ) and (E) quantified. ${ }^{*} \mathrm{P}<0.05,{ }^{* * *} \mathrm{P}<0.01$ and ${ }^{* * * *} \mathrm{P}<0.001$. miR, microRNA; CC, cervical cancer; NC, negative control.

expression is indicative of poor prognosis in patients with CC (30). Long intergenic non-coding RNA (LINC)00675 promotes CC cell proliferation, migration and invasion, and inhibits apoptosis via regulation of the $\mathrm{Wnt} / \beta$-catenin signaling pathway (31). FOXD3-AS1 serves a crucial role in certain types of cancer. For example, FOXD3-AS1 represses neuroblastoma progression by inhibiting poly(ADP-ribose) polymerase 1-mediated CCCTC-binding factor activation (8). In breast cancer, FOXD3-AS1 knockdown inhibits cancer cell proliferation, migration and invasion (9). To the best of our knowledge, the present study was the first to demonstrate that FOXD3-AS1 expression in CC tissues and cell lines was significantly upregulated compared with adjacent healthy cervical tissues and normal cervical epithelial cells, respectively. Moreover, upregulated FOXD3-AS1 expression was significantly associated with poor tumor differentiation, increased tumor size and lymph node metastasis in patients with CC. FOXD3-AS1 knockdown significantly inhibited CC cell malignant behaviour compared with the si-NC group, whereas FOXD3-AS1 overexpression displayed the opposite effect compared with the $\mathrm{NC}$ group. The aforementioned results indicated that FOXD3-AS1 displayed a tumor-promoting effect in CC.

miRNAs are important regulators involved in numerous aspects of cancer biology $(32,33)$. miR-128-3p is abnormally expressed in various types of cancer, where it is associated with promoting or inhibiting tumor progression. In glioma, miR-128-3p targets neuronal pentraxin 1 and regulates the Insulin receptor substrate 1/PI3K/AKT signaling pathway to repress glioma cell proliferation (34). Additionally, miR-128-3p suppresses drosha ribonuclease III to facilitate lung cancer cell migration (35). miR-128-3p inhibits liver cancer cell 

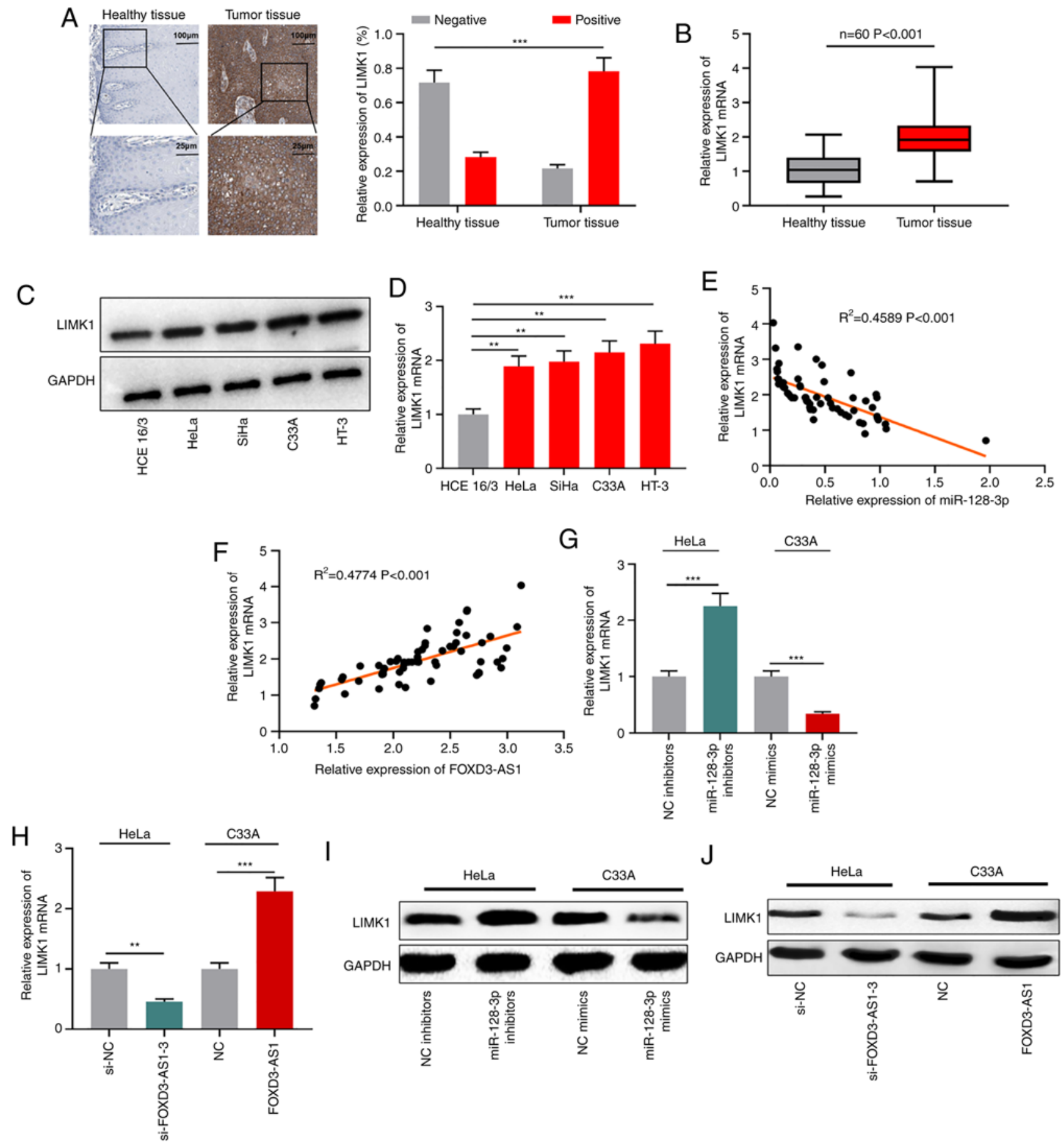

Figure 5. LIMK1 expression is regulated by the FOXD3-AS1/miR-128-3p axis in CC. (A) Immunohistochemistry was performed to detect LIMK1 protein expression levels in CC and adjacent healthy tissues. (B) RT-qPCR was performed to measure LIMK1 mRNA expression levels in CC and adjacent healthy tissues. (C) Western blotting was performed to measure LIMK1 protein expression levels in CC cells and HCE 16/3 cells. (D) RT-qPCR was performed to detect LIMK1 mRNA expression levels in normal cervical epithelial cells and CC cell lines. Pearson's correlation analysis was conducted to determine the correlation between (E) LIMK1 mRNA expression and miR-128-3p expression and between (F) LIMK1 mRNA expression and FOXD3-AS1 expression in CC tissues. RT-qPCR was performed to assess the regulatory effects of (G) miR-128-3p and (H) FOXD3-AS1 on LIMK1 mRNA expression levels. Western blotting was performed to determine the regulatory effects of (I) miR-128-3p and (J) FOXD3-AS1 on LIMK1 protein expression levels. ${ }^{* *} \mathrm{P}<0.01$ and ${ }^{* * * *} \mathrm{P}<0.001$. LIMK1, LIM domain kinase 1; FOXD3-AS1, forkhead box D3 antisense RNA 1; miR, microRNA; CC, cervical cancer; RT-qPCR, reverse transcription-quantitative PCR; NC, negative control; si, small interfering RNA.

proliferation by repressing phosphoinositide-3-kinase regulatory subunit 1 (36). The present study demonstrated that miR-128-3p expression was significantly reduced in CC tissues and cell lines compared with adjacent healthy tissues and normal cervical epithelial cells, respectively. Moreover, compared with the NC inhibitors group, miR-128-3p knockdown significantly facilitated CC cell proliferation, migration and invasion, suggesting that miR-128-3p displayed a suppressive effect on CC progression, which was consistent with a previous study (18). IncRNAs can directly interact with miRNAs and regulate the availability of their target miRNAs by serving as competing endogenous RNAs (26), a 
A

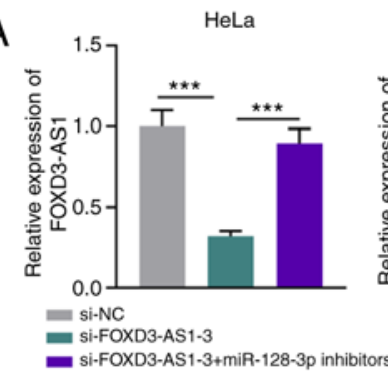

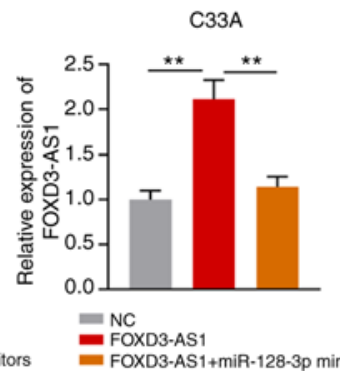

B

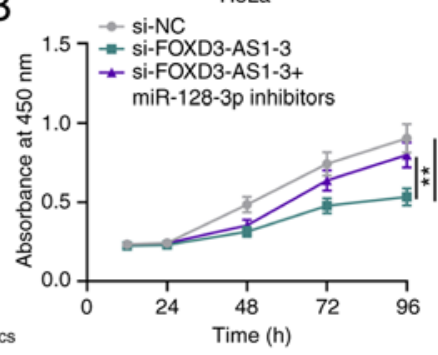

С33А

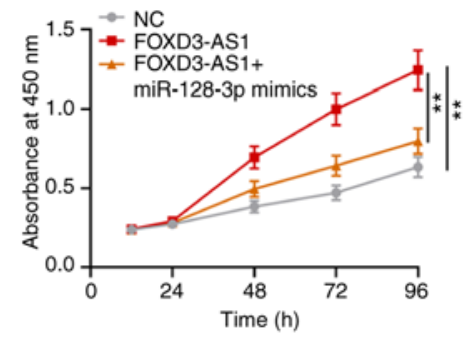

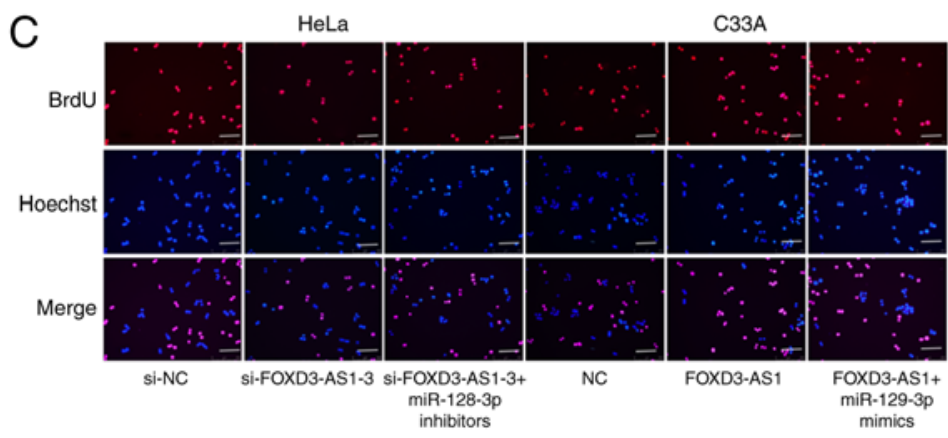
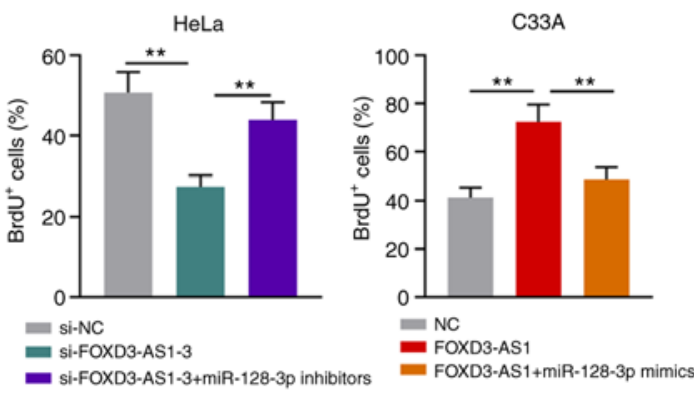

D
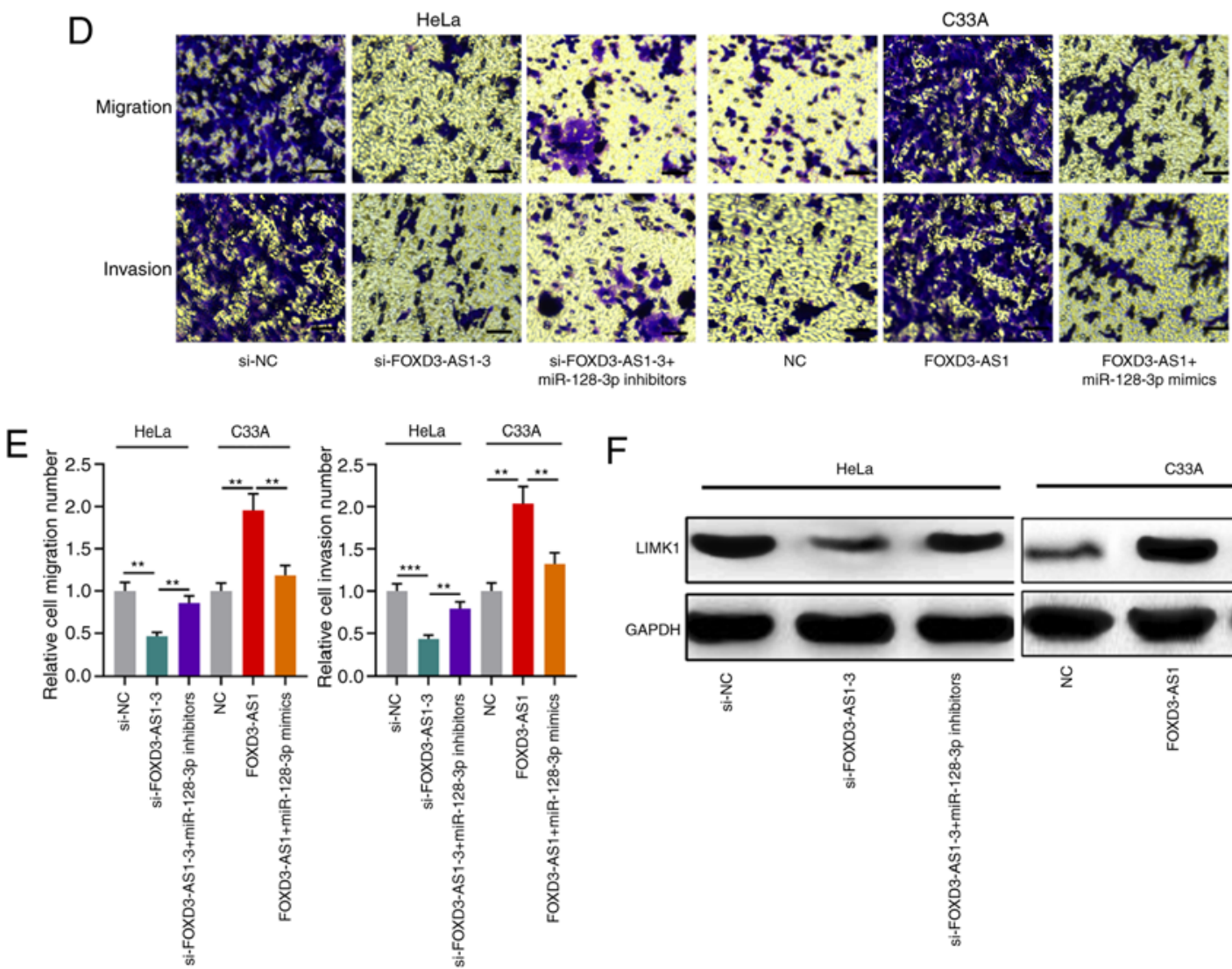

F

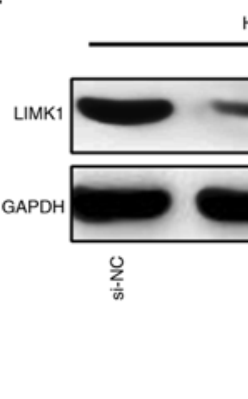

HeLa

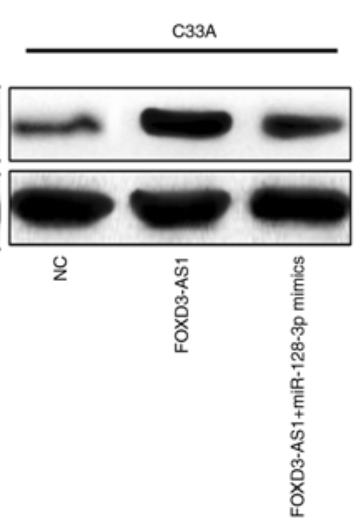

Figure 6. miR-128-3p partially reverses the effects of FOXD3-AS1. (A) FOXD3-AS1-knockdown HeLa cells were transfected with miR-128-3p inhibitors and FOXD3-AS1-overexpression C33A cells were transfected with miR-128-3p mimics. Subsequently, reverse transcription-quantitative PCR was performed to measure FOXD3-AS1 expression levels in CC cells. (B) Cell Counting Kit-8 and (C) BrdU assays (scale bar, $250 \mu \mathrm{m}$ ) were performed to determine CC cell proliferation. CC cell migration and invasion were (D) determined by performing Transwell assays (scale bar, $100 \mu \mathrm{m}$ ) and (E) quantified. (F) Western blotting was performed to measure LIMK1 protein expression levels in CC cells. ${ }^{* *} \mathrm{P}<0.01$ and ${ }^{* * *} \mathrm{P}<0.001$. miR, microRNA; FOXD3-AS1, forkhead box D3 antisense RNA 1; CC, cervical cancer; LIMK1, LIM domain kinase 1; si, small interfering RNA; NC, negative control.

mechanism that has received increasing attention in cancer research. For example, lncRNA HOXA cluster antisense RNA 2 facilitates non-small cell lung cancer progression by sponging miR-520a-3p (37). IncRNA double homeobox
A pseudogene 8 promotes renal cell cancer progression by repressing miR-126 (38). The present study identified a binding site between FOXD3-AS1 and miR-128-3p. Moreover, the results indicated that miR-128-3p was negatively regulated 
by FOXD3-AS1 in CC cells, confirming that the biological function of FOXD3-AS1 in CC was partly dependent on miR-128-3p.

LIMK1 phosphorylation may result in dynamic alterations to the cytoskeleton, thereby promoting cancer cell migration and invasion $(20,21)$. In ovarian cancer, LIMK1 knockdown results in decreased cancer cell migration and invasion (39). Additionally, LIMK1 interacts with myosin- 9 and $\alpha$-actinin- 4 , activating the PI3K/AKT signaling pathway and driving epithelial-to-mesenchymal transition of colorectal cancer cells, thus facilitating cancer progression (40). In prostate cancer, LIMK1 regulates actin polymerization via phosphorylation and inactivation of cofilin, and modulating cancer cell proliferation, cell cycle progression, migration, invasion and androgen receptor nuclear translocation (41). By performing immunohistochemical staining, the present study demonstrated that LIMK1 expression was significantly higher in CC tissues compared with adjacent healthy cervical tissues. Additionally, LIMK1 mRNA expression levels were notably higher in CC cells and tissues compared with the normal cervical cell line and adjacent healthy tissues, respectively. It has been reported that LIMK1 is a target of miR-128-3p in breast cancer (27). The present study demonstrated that LIMK1 mRNA expression was negatively associated with miR-128-3p expression, but positively associated with FOXD3-AS1 expression in CC tissues. LIMK1 was negatively regulated by miR-128-3p, which indirectly upregulated FOXD3-AS1 expression. The results suggested that FOXD3-AS1 may enhance LIMK1 expression by adsorbing miR-128-3p, thereby promoting the malignant phenotype of CC cells. However, there were a number of limitations to the present study, including the lack of in vivo experiments.

In summary, the results of the present study demonstrated that FOXD3-AS1 upregulated LIMK1 expression by targeting miR-128-3p, thereby facilitating CC cell proliferation, migration and invasion. Therefore, FOXD3-AS1 may serve as a potential therapeutic target and prognostic biomarker for patients with $\mathrm{CC}$.

\section{Acknowledgements}

Not applicable.

\section{Funding}

No funding was received.

\section{Availability of data and materials}

The datasets used and/or analyzed during the present study are available from the corresponding author on reasonable request.

\section{Authors' contributions}

XY and HD conceived and designed the study. XY, WB and $\mathrm{QL}$ performed the experiments. HS and QL analyzed the data. YX, DH and WB drafted the manuscript. XY and HD confirmed the authenticity of all the raw data. All authors read and approved the final manuscript.

\section{Ethics approval and consent to participate}

The present study was approved by the Ethics Review Board of Hengshui People's Hospital (approval no. H20150019). Written informed consent was obtained from all patients.

\section{Patient consent for publication}

Not applicable.

\section{Competing interests}

The authors declare that they have no competing interests.

\section{References}

1. Siegel RL, Miller KD and Jemal A: Cancer Statistics, 2017. CA Cancer J Clin 67: 7-30, 2017.

2. Maździarz A, Wygledowski J, Osuch B, Jagielska B and Śpiewankiewicz B: New directions in cervical cancer prophylaxis worldwide and in Poland-Case study of the polish rural female population. Ann Agric Environ Med 24: 592-595, 2017.

3. Small W Jr, Bacon MA, Bajaj A, Chuang LT, Fisher BJ, Harkenrider MM, Jhingran A, Kitchener HC, Mileshkin LR, Viswanathan AN and Gaffney DK: Cervical cancer: A global health crisis. Cancer 123: 2404-2412, 2017.

4. Chen J, Yu Y, Li H, Hu Q, Chen X, He Y, Xue C, Ren F, Ren Z, Li J, et al: Long non-coding RNA PVT1 promotes tumor progression by regulating the miR-143/HK2 axis in gallbladder cancer. Mol Cancer 18: 33, 2019.

5. Zhou C, Zhao J, Liu J, Wei S, Xia Y, Xia W, Bi Y, Yan Z and Huang H: LncRNA SNHG16 promotes epithelial- mesenchymal transition via down-regulation of DKK3 in gastric cancer. Cancer Biomark 26: 393-401, 2019

6. Xu Y, Li J, Wang P, Zhang Z and Wang X: LncRNA HULC promotes lung squamous cell carcinoma by regulating PTPRO via NF-кB. J Cell Biochem 120: 19415-19421, 2019.

7. Tong W, Han TC, Wang W and Zhao J: LncRNA CASC11 promotes the development of lung cancer through targeting microRNA-302/CDK1 axis. Eur Rev Med Pharmacol Sci 23: 6539-6547, 2019

8. Zhao X, Li D, Huang D, Song H, Mei H, Fang E, Wang X, Yang F, Zheng L, Huang $\mathrm{K}$ and Tong Q: Risk-associated long noncoding RNA FOXD3-AS1 inhibits neuroblastoma progression by repressing PARP1-mediated activation of CTCF. Mol Ther 26: 755-773, 2018.

9. Guan Y, Bhandari A, Xia E, Yang F, Xiang J and Wang O: lncRNA FOXD3-AS1 is associated with clinical progression and regulates cell migration and invasion in breast cancer. Cell Biochem Funct 37: 239-244, 2019.

10. Chen ZH, Hu HK, Zhang CR, Lu CY, Bao Y, Cai Z, Zou YX, $\mathrm{Hu}$ GH and Jiang L: Down-regulation of long non-coding RNA FOXD3 antisense RNA 1 (FOXD3-AS1) inhibits cell proliferation, migration, and invasion in malignant glioma cells. Am J Transl Res 8: 4106-4119, 2016.

11. Benz F, Roy S, Trautwein C, Roderburg C and Luedde T: Circulating MicroRNAs as biomarkers for sepsis. Int J Mol Sci 17: 78, 2016.

12. Zhou Y, Wang B, Wang Y, Chen G, Lian Q and Wang H: miR-140-3p inhibits breast cancer proliferation and migration by directly regulating the expression of tripartite motif 28 . Oncol Lett 17: 3835-3841, 2019.

13. Zhu X, Ma SP, Yang D, Liu Y, Wang YP, Lin T, Li YX, Yang SH, Zhang WC and Wang XL: miR-142-3p suppresses cell growth by targeting CDK4 in colorectal cancer. Cell Physiol Biochem 51: 1969-1981, 2018.

14. Zhou Q, Dong J, Luo R, Zhou X, Wang J and Chen F: MicroRNA-20a regulates cell proliferation, apoptosis and autophagy by targeting thrombospondin 2 in cervical cancer. Eur J Pharmacol 844: 102-109, 2019.

15. Wen F, Xu JZ and Wang XR: Increased expression of miR-15b is associated with clinicopathological features and poor prognosis in cervical carcinoma. Arch Gynecol Obstet 295: 743-749, 2017. 
16. Liang H, Luo R, Chen X, Zhao Y and Tan A: miR-187 inhibits the growth of cervical cancer cells by targeting FGF9. Oncol Rep 38: 1977-1984, 2017.

17. Juan C, Hua Q, Ruping Z and Tingting W: miRNA-489 as a biomarker in diagnosis and treatment of cervical cancer. Bratisl Lek Listy 119: 278-283, 2018.

18. Wang R, Liu L, Jiao J and Gao D: Knockdown of MIR4435-2HG suppresses the proliferation, migration and invasion of cervical cancer cells via regulating the miR-128-3p/MSI2 axis in vitro. Cancer Manag Res 12: 8745-8756, 2020.

19. Scott RW and Olson MF: LIM kinases: Function, regulation and association with human disease. J Mol Med (Berl) 85: 555-568, 2007.

20. Zhou Y, Ji J, Hong F, Zhuang J and Wang L: Maternal exposure to nanoparticulate titanium dioxide causes inhibition of hippocampal development involving dysfunction of the Rho/NMDAR signaling pathway in offspring. J Biomed Nanotechnol 15: 839-847, 2019.

21. Gong H, Zhou L, Khelfat L, Qiu G, Wang Y, Mao K and Chen W: Rho-associated protein kinase (ROCK) promotes proliferation and migration of PC-3 and DU145 prostate cancer cells by targeting LIM Kinase 1 (LIMK1) and matrix Metalloproteinase-2 (MMP-2). Med Sci Monit 25: 3090-3099, 2019.

22. Fu J, Yu J, Chen J, Xu H, Luo Y and Lu H: In vitro inhibitory properties of sesquiterpenes from Chloranthus serratus on cell motility via down-regulation of LIMK1 activation in human breast cancer. Phytomedicine 49: 23-31, 2018.

23. Zhang Y, Li A, Shi J, Fang Y, Gu C, Cai J, Lin C, Zhao L and Liu S: Imbalanced LIMK1 and LIMK2 expression leads to human colorectal cancer progression and metastasis via promoting $\beta$-catenin nuclear translocation. Cell Death Dis 9: 749, 2018.

24. Chhavi; Saxena M, Singh S, Negi MP, Srivastava AK, Trivedi R, Singh U, Pant MC and Bhatt ML: Expression profiling of G2/M phase regulatory proteins in normal, premalignant and malignant uterine cervix and their correlation with survival of patients. J Cancer Res Ther 6: 167-171, 2010.

25. Pfaffl MW: A new mathematical model for relative quantification in real-time RT-PCR. Nucleic Acids Res 29: e45, 2001.

26. Liu S, Zhang W, Liu K and Liu Y: LncRNA SNHG16 promotes tumor growth of pancreatic cancer by targeting miR-218-5p. Biomed Pharmacother 114: 108862, 2019.

27. Zhao J, Li D and Fang L: miR-128-3p suppresses breast cancer cellular progression via targeting LIMK1. Biomed Pharmacother 115: 108947, 2019.

28. Ding X, Jia X, Wang C, Xu J, Gao SJ and Lu C: A DHX9IncRNA-MDM2 interaction regulates cell invasion and angiogenesis of cervical cancer. Cell Death Differ 26: 1750-1765, 2019.

29. Jiang H, Liang M, Jiang Y, Zhang T, Mo K, Su S, Wang A, Zhu Y, Huang $G$ and Zhou R: The IncRNA TDRG1 promotes cell proliferation, migration and invasion by targeting miR-326 to regulate MAPK1 expression in cervical cancer. Cancer Cell Int 19: 152, 2019.
30. Feng S, Liu W, Bai X, Pan W, Jia Z, Zhang S, Zhu Y and Tan W: LncRNA-CTS promotes metastasis and epithelial-tomesenchymal transition through regulating miR-505/ZEB2 axis in cervical cancer. Cancer Lett 465: 105-117, 2019.

31. Ma S, Deng X, Yang Y, Zhang Q, Zhou T and Liu Z: The lncRNA LINC00675 regulates cell proliferation, migration, and invasion by affecting Wnt/ $\beta$-catenin signaling in cervical cancer. Biomed Pharmacother 108: 1686-1693, 2018

32. Liu Z, Li W, Pang Y, Zhou Z, Liu S, Cheng K, Qin Q, Jia Y and Liu S: SF3B4 is regulated by microRNA-133b and promotes cell proliferation and metastasis in hepatocellular carcinoma. EBioMedicine 38: 57-68, 2018.

33. Liu C, Jian M, Qi H and Mao WZ: MicroRNA 495 inhibits proliferation and metastasis and promotes apoptosis by targeting Twist1 in gastric cancer cells. Oncol Res 27: 389-397, 2019.

34. Huo L, Wang B, Zheng M, Zhang Y, Xu J, Yang G and Guan Q: miR-128-3p inhibits glioma cell proliferation and differentiation by targeting NPTX1 through IRS-1/PI3K/AKT signaling pathway. Exp Ther Med 17: 2921-2930, 2019.

35. Frixa T, Sacconi A, Cioce M, Roscilli G, Ferrara FF, Aurisicchio L, Pulito C, Telera S, Carosi M, Muti P, et al: MicroRNA-128-3p-mediated depletion of Drosha promotes lung cancer cell migration. Carcinogenesis 39: 293-304, 2018.

36. Huang CY, Huang XP, Zhu JY, Chen ZG, Li XJ, Zhang XH, Huang S, He JB, Lian F, Zhao YN and Wu GB: miR-128-3p suppresses hepatocellular carcinoma proliferation by regulating PIK3R1 and is correlated with the prognosis of HCC patients. Oncol Rep 33: 2889-2898, 2015.

37. Liu Y, Lin X, Zhou S, Zhang P, Shao G and Yang Z: Long noncoding RNA HOXA-AS2 promotes non-small cell lung cancer progression by regulating miR-520a-3p. Biosci Rep 39: BSR20190283, 2019.

38. Huang T, Wang X, Yang X, Ji J, Wang Q, Yue X and Dong Z: Long non-coding RNA DUXAP8 enhances renal cell carcinoma progression via downregulating miR-126. Med Sci Monit 24: 7340-7347, 2018

39. Chen P, Zeng M, Zhao Y and Fang X: Upregulation of Limk1 caused by microRNA-138 loss aggravates the metastasis of ovarian cancer by activation of Limk1/cofilin signaling. Oncol Rep 32: 2070-2076, 2014.

40. Liao Q, Li R, Zhou R, Pan Z, Xu L, Ding Y and Zhao L: LIM kinase 1 interacts with myosin-9 and alpha-actinin-4 and promotes colorectal cancer progression. Br J Cancer 117: 563-571, 2017.

41. Mardilovich K, Gabrielsen M, McGarry L, Orange C, Patel R, Shanks E, Edwards J and Olson MF: Elevated LIM kinase 1 in nonmetastatic prostate cancer reflects its role in facilitating androgen receptor nuclear translocation. Mol Cancer Ther 14: 246-258, 2015. International (CC BY-NC-ND 4.0) License. 